\title{
ESTUDO DA INFLUÊNCIA DA ADIÇÃO DE CINZA VOLANTE E RESÍDUO DA CONSTRUÇÃO CIVIL NAS PROPRIEDADES DA ARGAMASSA
}

\author{
R. C. de SOUSA ${ }^{1}$, A. M. P. F. FELIPE ${ }^{1}$, G. F. de FRANÇA ${ }^{1}$, P. A. A. COUTINHO ${ }^{1}$, J. A. S. \\ SOUZA $^{1}$. \\ ${ }^{1}$ Universidade Federal do Pará, Instituto de Tecnologia, Faculdade de Engenharia Química \\ E-mail para contato: robsoncs@yahoo.com.br
}

\begin{abstract}
RESUMO - A necessidade de acelerar o processo de gerenciamento de resíduos sólidos, assim como a possibilidade da elaboração de um material com um menor custo objetivou avaliar a utilização da cinza volante $(\mathrm{CV})$ e de resíduos da construção civil (RCC) na elaboração de argamassas. Após o beneficiamento dos resíduos formulou-se 5 traços com diferentes composições para submete-los à ensaios físicos, mecânicos e reológicos. Os ensaios físicos-mecânico mostraram um aumento da absorção e porosidade, e da diminuição da resistência à compressão da argamassa com o aumento do teor de cinza volante. Os ensaios reológicos mostraram que a incorporação da cinza volante resulta no aumento do torque em relação ao tempo de cura das argamassas, melhorando a trabalhabilidade do material.
\end{abstract}

\section{INTRODUÇÃO}

Estão sendo estudadas muitas maneiras de adicionar os resíduos industriais de uma forma alternativa na indústria da construção civil, oferecendo grande potencial para solucionar problemas do acúmulo do resíduo no meio ambiente, assim como a diminuição dos custos finais, como a incorporação de cinza volante. (Curtius et al., 2002)

Considerando o concreto no estado fresco as cinzas volantes possuem um papel muito importante, uma vez que ela melhora a coesão e a trabalhabilidade, diminuindo a exsudação e a segregação e aumentando o tempo de pega. Já no estado endurecido, a cinza volante contribui para a diminuição da temperatura devido às reações de hidratação que se apresentam inicialmente de forma mais lenta (Azevedo, 2002)

Estudar as propriedades reológicas da argamassa no estado fluído é de grande importância, no seu processamento e na sua aplicabilidade. (Ramachandran, 2001)

\section{OBJETIVOS}

Avaliar os aspectos físicos, mecânicos e reológicos de formulações de argamassas elaboradas com a reciclagem de resíduo da construção civil e cinza volante, em substituição parcial do cimento Portland. 


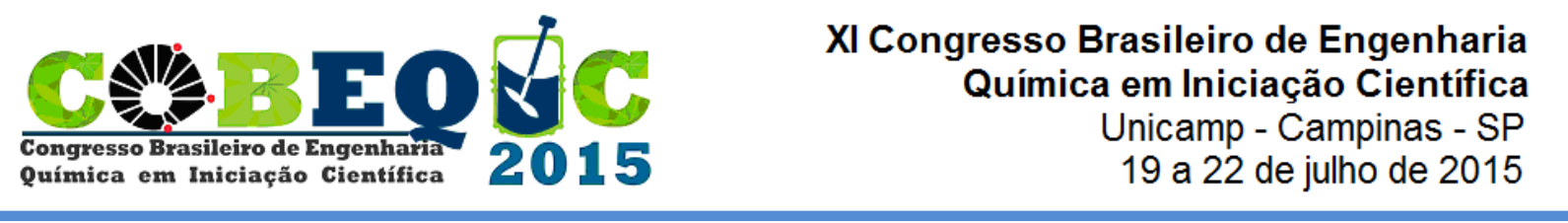

\section{MATERIAIS E MÉTODOS}

Após a aquisição o RCC foi submetido ás operações unitárias de cominuição e classificação. Inicialmente o material foi britado no britador de mandíbulas Briterpa (Modelo 1020 - Série 08), e moído no moinho de bolas (Modelo CIMAQ S.A. IND. COM.). Após esses processos o material foi classificado por peneiramento para enquadra-lo como um agregado miúdo de acordo com a norma ABNT NBR 7211. A sílica também foi classificada por peneiramento, e tanto na análise com o RCC quanto com a sílica, o material passante da peneira de \#100 $(150 \mu \mathrm{m})$ foi separado para ser usado na produção dos corpos de prova de argamassa e nos traços elaborados para os ensaios reológicos.

A cinza volante foi proveniente da refinaria de alumina Norsk Hydro (Barcarena - PA), gerada a partir da combustão do carvão mineral. Utilizou-se o cimento Portland tipo CP IIE32 pois o mesmo apresenta pouca adição de pozolanas.

\subsection{Elaboração Das Amostras}

Os traços de argamassas elaboradas para o estudo estão obedecendo as proporções da tabela 1. Os materiais foram homogeneizados em um misturador mecânico marca SOLDTEST durante cinco minutos e em seguida foram dosados em moldes cilíndricos de diâmetro de cinco centímetros e altura dez centímetros.

Tabela 1- Composição dos materiais utilizados da elaboração dos traços

\begin{tabular}{cccccc}
\hline Traços & $\begin{array}{c}\text { RCC } \\
(\mathbf{\%})\end{array}$ & $\begin{array}{c}\text { Cimento } \\
(\mathbf{\%})\end{array}$ & $\begin{array}{c}\text { Cinza } \\
(\mathbf{\%})\end{array}$ & $\begin{array}{c}\text { Sílica } \\
(\mathbf{\%})\end{array}$ & $\begin{array}{c}\text { H2O } \\
\mathbf{( \% )}\end{array}$ \\
\hline Tr1 & 80 & 5 & 15 & - & 35 \\
Tr2 & 75 & 5 & 20 & - & 35 \\
Tr3 & 40 & 5 & 30 & 25 & 35 \\
Tr4 & 30 & 5 & 40 & 25 & 35 \\
Tr5 & 20 & 5 & 50 & 25 & 35 \\
Nota: Na preparação das amostras utilizou-se 65\% de sólidos. 35\% de H2O referem-se ao valor total. \\
\hline
\end{tabular}

\subsection{Ensaios Físicos-mecânico}

Os corpos de prova ficaram em processo de cura por um período de 28 dias. Após esses dias foram realizados os ensaios de absorção aparente, porosidade aparente, massa específica e resistência à compressão de acordo com a ABNT NBR 9778 e 13281, com o objetivo de avaliar as propriedades das argamassas produzidas, principalmente na avaliação da cinza volante como aglomerante.

\subsection{Parâmetros Das Análises Reológicas}

Realizou-se os ensaios reológicos dos traços 1 e 2 utilizando o viscosímetro rotacional modelo Haake VT 550, acoplado ao sistema de configuração de cilindros coaxiais copo SV e cilindros SV1. Os softwares utilizados nas análises foram o Reowin Job Manager e o Reowin Data Manager. 
Para a elaboração da curva (Torque versus Tempo) programou-se uma taxa de $53,4 \mathrm{~s}^{-1}$ em intervalos de $15 \mathrm{~min}$ cada analise a uma temperatura de $28^{\circ} \mathrm{C}$, utilizando a metodologia de rampa controlada CR (ControlledRamp). Para a obtenção das curvas de fluxo utilizaram-se taxas de 0 a $600 \mathrm{~s}^{-1}$, no tempo de 120 segundos e a uma temperatura de $28^{\circ} \mathrm{C}$.

\section{RESULTADOS E DISCUSSÃO}

\subsection{Análise Granulométrica do RCC}

Os resultados da analise granulométrica do resíduo da construção civil estão apresentados na figura 1. Após o beneficiamento o material apresentou um $\mathrm{D}_{50}$ de $135 \mu \mathrm{m}$, o que foi possível enquadrá-lo como um agregado miúdo.

Figura 1- Análise granulométrica do resíduo da construção civil.

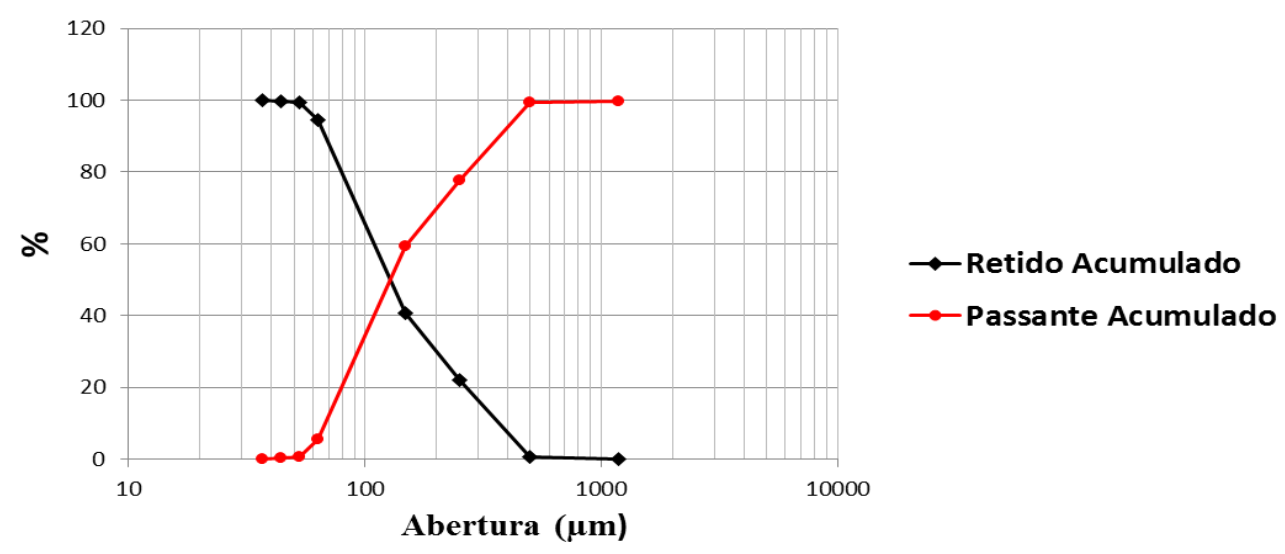

\subsection{Ensaios Físicos-mecânico}

A tabela 2 mostra um aumento na absorção aparente à medida que se aumenta o teor de cinza volante. Esse aumento pode estar relacionado ao aumento da quantidade de finos incorporados, resultando em um aumento do número de vazios nos corpos de prova. Como consequência disso a argamassa absorverá mais água. O mesmo fato justifica o aumento da porosidade aparente com o aumento gradual do teor de cinza volante. Segundo Scandarola (2010) a água em excesso na argamassa não irá reagir na formação de hidratos, e a mesma será expelida formando vazios na matriz de cimento endurecida.

Observou-se decréscimo na massa específica à medida que se aumenta o teor de cinza volante nos traços. Este fato está relacionado à diminuição da massa específica da mistura em geral. Nos resultados de resistência à compressão observa-se que com o aumento do teor de cinza volante ocorre uma redução da resistência das argamassas. Angelim et al., (2003) observaram que com o aumento de finos ás argamassas tendem a diminuir a sua resistência mecânica. É possível averiguar esta observação fazendo a comparação entre os traços sem sílica $(1,2)$, e entre os traços com sílica $(3,4,5)$. 
Tabela 2 - Resultado dos ensaios físicos-mecânico

\begin{tabular}{ccccccccc}
\hline Traço & $\begin{array}{c}\text { Teor } \\
\text { sílica } \\
(\%)\end{array}$ & $\begin{array}{c}\text { Teor } \\
\text { RCC } \\
(\%)\end{array}$ & $\begin{array}{c}\text { Teor } \\
\mathbf{C V} \\
\mathbf{( \% )}\end{array}$ & $\begin{array}{c}\text { Teor } \\
\text { cimento } \\
\mathbf{( \% )}\end{array}$ & $\begin{array}{c}\text { Absorção } \\
\mathbf{( \% )}\end{array}$ & $\begin{array}{c}\text { Porosidade } \\
\mathbf{( \% )}\end{array}$ & $\begin{array}{c}\text { Massa } \\
\text { Específica } \\
\left(\mathbf{g} / \mathbf{c m}^{3}\right)\end{array}$ & $\begin{array}{c}\text { Resistência } \\
\text { à } \\
\text { compressão } \\
(\mathbf{M P a})\end{array}$ \\
\hline $\operatorname{Tr} 1$ & - & 80 & 15 & 5 & 23,55 & 30,62 & 1,30 & 0,90 \\
$\operatorname{Tr} 2$ & - & 75 & 20 & 5 & 28,76 & 36,63 & 1,27 & 0,43 \\
$\operatorname{Tr} 3$ & 25 & 40 & 30 & 5 & 35,49 & 43,82 & 1,23 & 1,13 \\
$\operatorname{Tr} 4$ & 25 & 30 & 40 & 5 & 39,86 & 47,69 & 1,22 & 0,98 \\
$\operatorname{Tr} 5$ & 25 & 20 & 50 & 5 & 41,61 & 48,76 & 1,17 & 0,92 \\
\hline
\end{tabular}

\subsection{Resultados Das Análises Reológicas}

A figura 2 mostra estudos preliminares das curvas de trabalhabilidade para os traços $1 \mathrm{e}$ 2. Nela é possível observar um aumento no torque de acordo com o tempo de execução dos experimentos, melhorando o fator de trabalhabilidade do material. $\mathrm{O}$ aumento da absorção de água é uma das explicações para o acréscimo do torque em relação ao tempo de execução do ensaio. A associação da mistura de cinza volante e resíduo da construção civil, que possuem granulometrias bastante finas, é uma explicação para esse aumento da absorção de água, pois quando misturados à água formam estruturas tridimensionais (alitas e belitas), durante o processo de cura da argamassa.

Figura 2 - Curva (Torque vs Tempo) para os Traços 1 e 2.

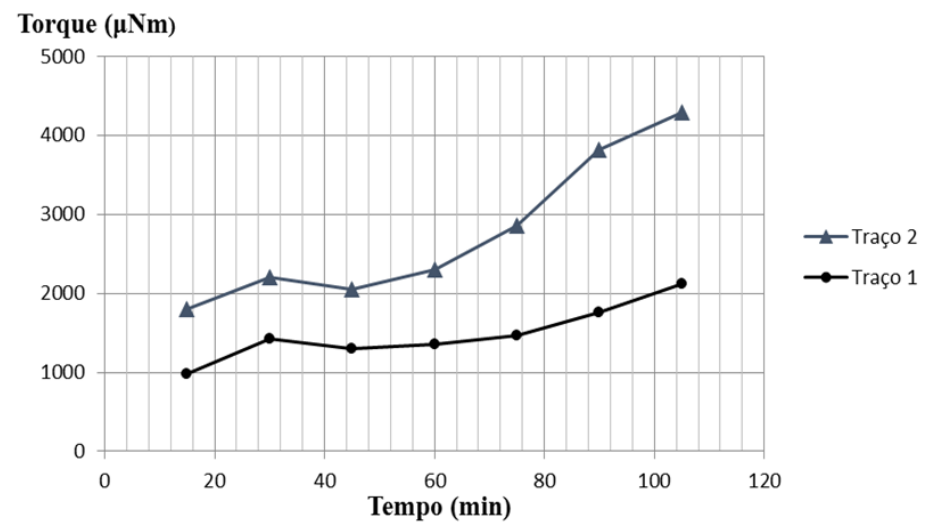

Nas figuras 3 e 4 estão as curvas de fluxo obtidas para as formulações dos traços 1 e 2 . Com a elaboração dessas curvas é possível confirmar o que os estudos da literatura mostram para sistemas constituídos por partículas sólidas em suspensão. Os traços se comportam como fluidos não-newtonianos dependentes do tempo. Observa-se que com o aumento da taxa de cisalhamento ocorre uma diminuição da viscosidade da argamassa. No traço 2, o qual possui maior teor de cinza volante quando comparado ao traço 1, observa-se maiores valores de tensão de cisalhamento e viscosidade decorrente da maior concentração de cinza volante. 
Figura 3 - Perfil das curvas de fluxo para os Traços 1 e 2.

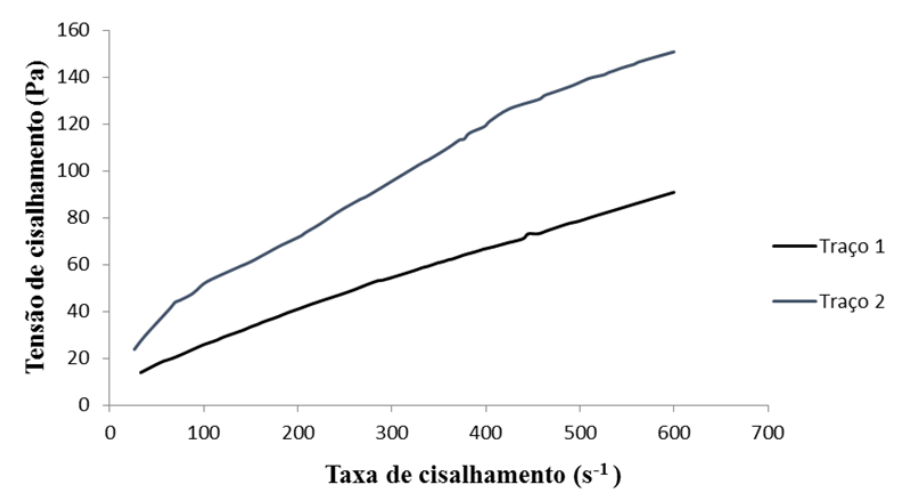

Figura 4 - Viscosidade aparente versus taxa de cisalhamento para os Traços 1 e 2.

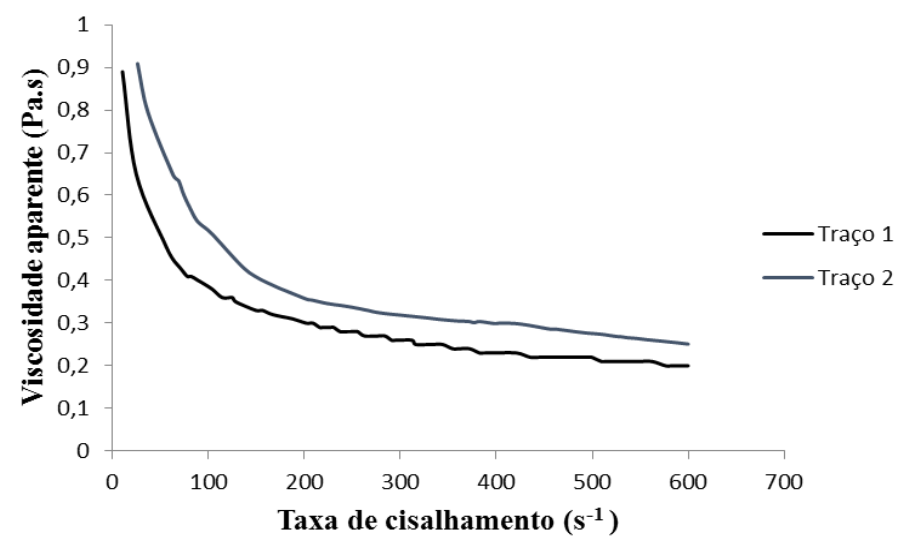

A tabela 5 apresenta os parâmetros do ajuste de curva para o traço 1, e mostra que argamassa tem uma melhor correlação com modelo reológico de Herschel-Bulkley.

Tabela 3 - Parâmetros dos modelos reológicos de Bingham e Herschel-Bulkley

\begin{tabular}{|c|c|c|c|c|c|c|c|}
\hline Modelo & \multicolumn{3}{|c|}{ Bingham } & \multicolumn{4}{c|}{ Herschel-Bulkley } \\
\hline Parâmetros & $\tau_{0(\mathrm{~Pa})}$ & $n_{P(\mathrm{~Pa} . \mathrm{s})}$ & $R^{2}$ & $\tau_{0}(\mathrm{~Pa})$ & $\mathrm{K}$ & $\mathrm{n}$ & $R^{2}$ \\
\hline $\operatorname{Tr} 1$ & 28,64 & 0,2169 & 0,9959 & 13,53 & 1,070 & 0,7632 & 0,9985 \\
\hline
\end{tabular}

\section{CONCLUSÃO}

Os ensaios físicos-mecânico nos cinco traços mostraram que com a adição de cinza volante se obtém maiores valores de absorção aparente e porosidade aparente. No ensaio de resistência à compressão obtiveram-se valores menores de resistência com o aumento do teor de cinza, entretanto esses resultados são razoáveis comparando-os as exigências da ABNT NBR 13281, e levando em consideração que utilizou-se apenas 5\% de cimento para se ter uma maior dimensão da atividade pozolânica da cinza volante. 
A reologia dos traços 1 e 2 mostrou que com o aumento do teor de cinza volante ocorreu um aumento do torque em relação ao tempo de ensaio e uma maior absorção de água pelo sistema, melhorando com isso a trabalhabilidade da argamassa. Em relação ao modelo matemático, o modelo de Hershel-Bulkley foi que apresentou melhores parâmetros para a representação reológica da argamassa elaborada.

Os resultados demonstram uma possibilidade de incluir esses resíduos na elaboração de argamassas, contribuindo de maneira promissora para o destino dos mesmos no meio ambiente, visto que nos dias de hoje há grandes dificuldades enfrentadas no destino correto dos resíduos sólidos gerados pela construção civil e indústrias minero-metalúrgica.

\section{REFERÊNCIAS}

ANGELIM, R. R.; ANGELIM, S. C. M.; CARASEK, H. Influência da adição de finos calcários, silicosos e argilosos nas propriedades das argamassas e dos revestimentos. In: SIMPÓSIO BRASILEIRO DE TECNOLOGIA DAS ARGAMASSAS, V., 2003, São Paulo. Anais. São Paulo: ANTAC, p. 383-398, 2003.

AZEVEDO, A.F.F.L.C. Betões de elevado desempenho com incorporações de Cinzas Volantes. 2002. Dissertação de Doutorado em Engenharia Civil-Escola de Engenharia, Universidade do Minho, Braga, Portugal.

CURTIUS, A. J.; FIEDLER, H. D. Análise de metais e qualidade analítica. Meio ambiente e carvão: impactos da exploração e utilização. Porto Alegre: FEPAM, p. 211-227, 2002.

NBR 13281: Argamassa para assentamento e revestimento de paredes e tetos - Requisitos. Rio de Janeiro, 2005.

NBR 7211: Agregados para concreto - especificação. Rio de Janeiro, 2005.

NBR 9778: Argamassa e concreto endurecidos - Determinação da absorção de agua por imersão, índice de vazios e massa especifica. Rio de Janeiro, 1987.

SCANDOLARA, J. P., Propriedades de argamassas obtidas pela substituição parcial de cimento Portland por rejeitos particulados de tijolo. 2010. Dissertação (Mestrado em Ciência e Engenharia dos Materiais) - Universidade do Estado de Santa Catarina, Centro de Ciências Tecnológicas - CCT, Joinville.

RAMACHANDRAN, V.S., BEAUDOIN, J.J. Handbook of analytical techniques in concrete science and technology, New York, Noyes / William Andrew, 2001. 